\title{
ANALISIS PENGARUH KUALITAS PELAYANAN YANG DIMEDIASI \\ OLEH PERCEIVED VALUE TERHADAP KEPUTUSAN PEMBELIAN ULANG PENGGUNA KARTU PERDANA TELKOMSEL
}

\author{
Ni Ketut Murdani ${ }^{1}$ \\ Ni Wayan Ardani ${ }^{2}$ \\ Kadek Pradnya Prayoga ${ }^{3}$ \\ Program Studi Manajemen , Fakultas Ekonomi, \\ Universitas Mahendradatta Bali \\ Jl. Ken Arok No. 12 Peguyangan Denpasar Utara, Bali 80115
}

\begin{abstract}
ABSTRAK
Penelitian ini bertujuan menganalisa pengaruh kualitas pelayanan yang dimediasi perceived value terhadap keputusan pembelian ulang konsumen, karena dari tahun 2017 - tahun 2018 kartu selular Telkom sel mngalami penurunan pembelian. Serta perbedaan antara pengaruh kualitas pelayanan dan pengaruh nilai keuntungan (perceived value) terhadap keputusan pembelian ulang kartu perdana Telkomsel. Sampel dalam penelitian ini sebanyak 100 orang responden Mahasiswa di Kota Denpasar yang menggunakan kartu perdana Telkomsel. Dengan menggunakan metode Convenience sampling. Teknik analisis data yang digunakan dalam penelitian ini adalah analisis regresi berganda.

Hasil penelitian ini membuktikan bahwa kualitas pelayanan tidak terlalu berpengaruh terhadap keputusan pembelian ulang kartu perdana Telkomsel karena konsumen lebih memikirkan nilai keuntungan daripada layanan yang disediakan ketika memakai kartu perdana Telkomsel. Para konsumen hanya memakai layanan yang diperlukan saja dan jika layanan tersebut memberikan keuntungan pada mereka. Terdapat hubungan yang signifikan antara perceived value dan keputusan pembelian ulang kartu perdana Telkomsel.
\end{abstract}

Kata Kunci :Kualitas Pelayanan, Perceived Value, Layanan Yang Disediakan, Keputusan Pembelian Ulang

Ni Ketut Murdani

Ni Wayan Ardani

Kadek Pradnya Prayoga 


\begin{abstract}
This study purposed to analyze the influence of mediated service quality perceived value on consumer repurchase decisions, and the difference between the effect of service quality and the effect of perceived value on the decision to repurchase Telkomsel starter cards. The sample in this study were 100 students from Denpasar City who used Telkomsel starter cards. By using the Convenience sampling method. The data analysis technique used in this study is multiple regression analysis.

The results of this study prove that service quality is not too influential on the decision to repurchase Telkomsel starter cards because consumers think more about the value of benefits than the services provided when using Telkomsel starter cards. Consumers only use services that are needed and if the service benefits them. There is a significant relationship between perceived value and the decision to repurchase Telkomsel starter cards.
\end{abstract}

Keywords: Service Quality, Perceived Value, Services Provided, Repurchase Decisions

\section{PENDAHULUAN}

Dunia bisnis seluler saat ini diwarnai oleh persaingan yang ketat dimana perusahaan selular harus mampu untuk siap bersaing dengan perusahaan lain demi mempertahankan pangsa pasar dan meningkatkan kegiatan usahanya. Kualitas Pelayanan yang semakin baik merupakan faktor yang berharga dalam dunia jasa selular karena dapat menjadi faktor terpenting dalam menentukan kepuasan pelanggan. Perusahaan juga perlu memahami nilai yang diinginkan oleh pelanggan, sehingga perusahaan bisa memberikan suatu nilai sesuai dengan apa yang dibutuhkan pelanggannya, agar mereka mau membeli produk yang ditawarkan. (Gantara, 2013).

Memasuki era digital, Telkomsel terus mengembangkan bisnis digital, diantaranya Digital Advertising,
Digital Lifestyle, Mobile Financial Services, dan Internet of Things. Untuk melayani kebutuhan pelanggan, Telkomsel menggelar call center 24 jam dan layanan GraPARI yang tersebar di seluruh Indonesia.

Namun Pendapatan Telkomsel di 2018 turun 4,3 persen dibanding setahun sebelumnya. Capaian Telkomsel itu senada dengan situasi industri telekomunikasi yang pendapatannya anjlok 7,3 persen. Direktur Utama Telkomsel Ririek Adriansyah mengatakan turunnya pendapatan Telkomsel dianggap sebagai pelajaran untuk membenahi diri dan meningkatkan kualitas pelayanan agar tidak mengalami kejadian serupa di tahun ini dan di masa yang akan datang.

Berdasarkan dengan pemaparan uraian di atas, maka peneliti menetapkan tujuan dari penelitian ini,

Ni Ketut Murdani

Ni Wayan Ardani

Kadek Pradnya Prayoga 
yakni; untuk menjelaskan pengaruh Kualitas Pelayanan terhadap keputusan pembelian ulang; untuk menjelaskan pengaruh kualitas pelayanan terhadap perceived value; untuk menjelaskan pengaruh perceived value terhadap keputusan pembelian ulang; dan untuk menjelaskan peran perceived value dalam memediasi pengaruh kualitas pelayanan terhadap keputusan pembelian ulang.

\section{Pengertian Kualitas Pelayanan}

Menurut Sulistiono (2010) "Kualitas pelayanan adalah segala bentuk pelayanan yang diberikan oleh pihak retail kepada konsumen". Parasuraman, et al., (1988), mengidentifikasikan 5 (lima) dimensi pokok tentang kualitas pelayanan. Dimensi pokok tersebut adalah : 1) Tangibles (Bukti Langsung) Meliputi penampilan dan performansi dari fasilitas-fasilitas fisik, perlatan, personel, dan material-material komunikasi yang digunakan dalam proses penyampaian layanan; 2) Reliability (Keandalan) Kemampuan pihak penyedia jasa dalam memberikan jasa atau pelayanan secara tepat dan akurat sehingga pelanggan dapat mempercayai dan mengandalkannya; 3) Reponsiveness (Daya Tanggap) Kemauan atau keinginan pihak penyedia jasa untuk segera memberikan bantuan pelayanan yang dibutuhkan dengan cepat; dan 4) Assurance (Jaminan) Pemahaman dan sikap kesopanan dari karyawan (contact personel) dikaitkan dengan kemampuan mereka dalam memberikan keyakinan kepada pelanggan bahwa pihak penyedia jasa mampu memberikan pelayanan dengan sebaikbaiknya.

\section{Pengertian Perceived Value}

Perceived Value adalah konsep yang sangat subjektif. Didefinisikan secara luas bahwa Perceived Value adalah hasil atau manfaat yang diterima oleh pelanggan yang berkaitan dengan total biaya (termasuk harga yang dibayar ditambah biaya lain yang terkait dengan pembelian) (Woodruff, 1997). Namun apa yang merupakan nilai tampaknya memiliki sifat yang personal, istimewa dan sangat bervariasi dari satu pelanggan ke pelanggan lain (Zeithaml, 1988 ;13). Untuk itu maka Perceived Value juga sering dikatakan sebagai penilaian pribadi (Xu, 2009).

Menurut Sweeney dan Soutar (2010:8) dimensi persepsi nilai terdiri empat aspek utama: 1) Emotional Value, yaitu utilitas yang berasal dari perasaan atau afektif/ emosi positif yang ditimbulkan dari mengkonsumsi produk; 2) Social Value, yaitu utilitas yang didapatkan dari kemampuan produk untuk meningkatkan konsep diri-sosial pelanggan; 3) Quality/Performance Value, yaitu utilitas yang diperoleh dari persepsi terhadap kualitas dan kinerja yang diharapkan atas produk; 4) Price/Value of Money, yakni utilitas yang didapatkan dari produk dikarenakan reduksi biaya jangka pendek dan biaya jangka panjang.

\section{Pengertian Minat Pembelian Ulang}

Minat Pembelian Ulang sebagai Perilaku Pembelian yang mengukur kecenderungan untuk melanjutkan , meningkatkan dan mengurangi jumlah layanan dari pemasok saat ini. Keputusan Pembelian Ulang mengacu pada kemungkinan dalam

Ni Ketut Murdani

Ni Wayan Ardani

Kadek Pradnya Prayoga 
menggunakan penyedia layanan kembali dimasa depan (Fornell, 1992;Mosavi dan Ghaedi, 2011;252). Pada dasarnya Keputusan Pembelian Ulang adalah perilaku pelanggan dimana pelanggan merespon secara positif terhadap kualitas pelayanan suatu perusahaan dan berniat melakukan kunjungan kembali atau mengkonsumsi kembali produk perusahaan tersebut (Cronin et al., 1992).

Menurut Schiffman dan Kanuk terdapat dua tipe pembelian konsumen, yaitu pembelian percobaan dan pembelian ulang. Kondisi dimana konsumen membeli suatu produk (atau merek) untuk pertama kali dan dalam jumlah kecil, dapat dikatakan sebagai pembelian percobaan (trial purchases). Pembelian ulang (repeat purchases) adalah kegiatan mengkonsumsi kembali suatu produk karena kepuasan yang diciptakan dan dalam jumlah besar. Menurut Keller minat beli ulang dapat diidentifikasi melalui indikator-indikator sebagai berikut: 1) Minat transaksional : yaitu kecenderungan seseorang untuk selalu membeli ulang produk yang telah dikonsumsinya; 2) Minat referensial : yaitu kecenderungan seseorang untuk mereferensikan produk yang sudah dibelinya, agar juga dibeli oleh orang lain, dengan referensi pengalaman konsumsinya; 3) Minat preferensial : yaitu minat yang menggambarkan perilaku seseorang yang selalu memiliki preferensi utama pada produk yang telah dikonsumsi. Preferensi ini hanya dapat diganti bila terjadi sesuatu dengan produk preferensinya; 4) Minat eksploratif : minat ini menggambarkan perilaku seseorang yang selalu mencari informasi mengenai produk yang diminatinya dan mencari informasi untuk mendukung sifat-sifat positif dari produk yang menjadi target utamanya.

\section{METODE PENELITIAN}

Penelitian dengan menggunakan metode asosiatif, dimana untuk mengetahui sebab akibat dari variabel yang memengaruhi terhadap variabel yang dipengaruhi. Sampel dalam penelitian ini sebanyak 100 orang responden Mahasiswa di Kota Denpasar yang menggunakan kartu perdana Telkomsel. Dengan menggunakan metode Convenience sampling. Teknik analisis data yang digunakan dalam penelitian ini adalah analisis regresi berganda.

\section{HASIL PENELITIAN}

Berdasarkan nilai-nilai tersebut, maka persamaan regresi linier berganda adalah : $\mathrm{Y}=2,598-0,367$ $\mathrm{X} 1+1,139 \mathrm{X} 2$. Ini berarti bahwa : $\mathrm{a}=$ 2,598 artinya apabila variabel $\mathrm{X} 1$ dan variabel X2 tidak berubah atau konstan maka $\mathrm{Y}$ akan sebesar 2,598; b1 = sebesar - 0,367 artinya apabila variabel $\mathrm{X} 1$ di naikkan dan variabel $\mathrm{X} 2$ tetap maka variabel $\mathrm{Y}$ akan berkurang sebesar 0,$367 ; b 2=$ sebesar 1,139 artinya apabila variabel X2 di naikkan dan variabel $\mathrm{X} 1$ tetap maka variabel $\mathrm{Y}$ akan bertambah sebesar 1,139.

\section{Uji t (Uji Partial)}

Uji ini digunakan untuk mengetahui besarnya pengaruh dari masing-masing variabel dependen secara parsial terhadap variabel dependen. Berdasarkan hasil pengolahan dengan menggunakan software SPSS for windows versi 25

Ni Ketut Murdani

Ni Wayan Ardani

Kadek Pradnya Prayoga 
dapat dikatahui bahwa nilai t hitung dari variabel Kualitas Pelayanan (X1) sebesar -3.679 dan nilai signifikansinya adalah sebesar $0,000<\alpha=0,05$ sehingga disimpulkan bahwa secara parsial terdapat pengaruh antara variabel Kualitas Pelayanan (X1) terhadap Keputusan Pembelian Ulang (Y). Selain itu dapat diketahui juga bahwa nilai $\mathrm{t}$ hitung dari Perceived
Value (X2) sebesar 6.860 dan nilai signifikannya adalah sebesar $0,000<\alpha$ $=0,05$ sehingga dapat disimpulkan bahwa secara parsial terdapat pengaruh secara signifikan antara Perceived Value terhadap variabel Keputusan Pembelian Ulang (Y).

Untuk lebih jelasnya, dapat dilihat pada gambar kurva normal di bawah ini

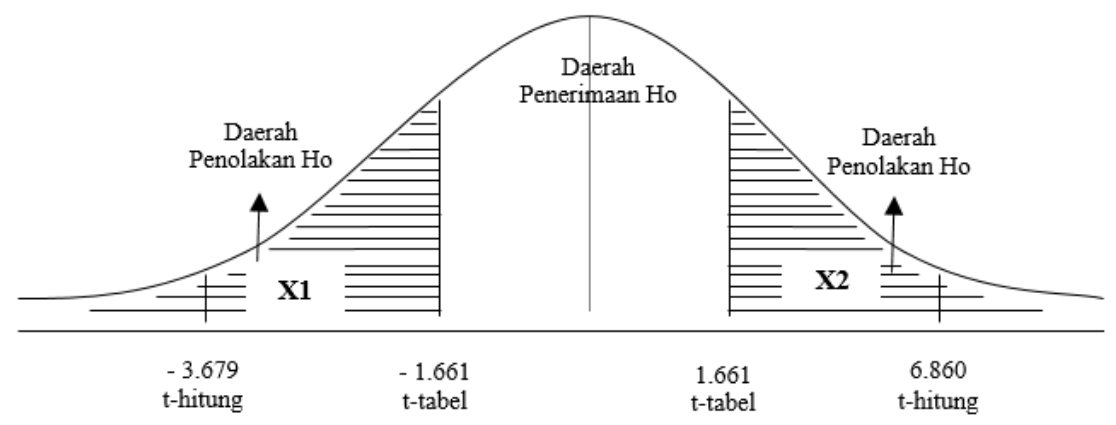

Gambar 1 Kurva Distribusi t

\section{Uji F (Uji Simultan)}

Uji ini digunakan untuk mengetahui besarnya pengaruh dari masing-masing variabel independen secara simultan terhadap variabel dependen.
Berdasarkan hasil dari pengolahan dengan menggunakan software SPSS for windows versi 25 dapat dilihat pada tabel di bawah ini.

\section{Tabel 4.1 Hasil Analisis Uji F}

\begin{tabular}{|c|c|c|c|c|c|c|}
\hline \multicolumn{7}{|c|}{ ANOVA $^{\text {a }}$} \\
\hline \multirow{3}{*}{1} & Model & Sum of Squares & df & Mean Square & F & Sig. \\
\cline { 2 - 7 } & Regression & 256.432 & 2 & 128.216 & 24.102 & $.000^{\text {b }}$ \\
\cline { 2 - 7 } & Residual & 516.008 & 97 & 5.320 & & \\
\hline & Total & 772.440 & 99 & & & \\
\hline
\end{tabular}

Sumber : Lampiran 7, data primer yang diolah

Ni Ketut Murdani

Ni Wayan Ardani

Kadek Pradnya Prayoga 
Pada Tabel 4.1 dapat diketahui bahwa pengujian pengaruh variabel bebas secara bersama-sama terhadap variabel terikatnya dengan menggunakan uji $\mathrm{F}$. Hasil perhitungan statistik menunjukan nilai Fhitung $=24,102>$ Ftabel $=3,090$ (berasal dari Tabel F) dengan menggunakan batas signifikansi 0,05 maka diperoleh nilai signifikansi tersebut lebih kecil dari 0,05, sehingga dapat disimpulkan bahwa terdapat pengaruh secara simultan variabel Kualitas Pelayanan (X1) dan variabel Perceived Value (X2) terhadap variabel Keputusan Pembelian Ulang (Y).

Dengan Kurva penerimaan dan penolakan Ho Kualitas Pelayanan dan Perceived Value terhadap Keputusan Pembelian Ulang dapat dilihat dari gambar dibawah ini.

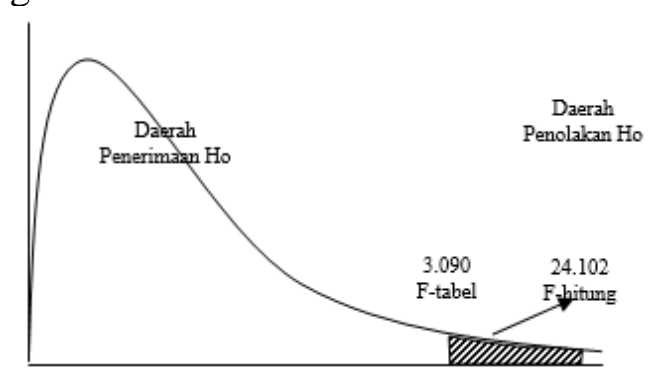

Dari Tabel 10 dan Gambar 4.1 didapat bahwa Fhitung yaitu 24,102 lebih besar dari Ftabel 3,090 . artinya hipotesis diterima, variabel Kualitas Pelayanan (X1) dan Perceived Value (X2) secara bersama sama (simultan) berpengaruh signifikan terhadap Keputusan Pembelian Ulang di kalangan mahasiswa penggunakartu perdana Telkomsel

\section{PEMBAHASAN}

\section{Pengaruh Kualitas Pelayanan Terhadap Keputusan Pembelian Ulang.}

Berdasarkan hasil analisis data yang dilakukan dengan yang pertama dengan analisis korelasi didapatkan hasil X1 dan Y sebesar 0,089 dengan signifikan 0,379 sehingga dapat dikatakan Kualitas Pelayanan memiliki korelasi yang sangat rendah terhadap Keputusan Pembelian Ulang, kedua dari perhitungan uji t Nilai $\mathrm{t}-$

hitung X1 -3,679 lebih kecil dari t-tabel $(1,661)$, maka Ho ditolak dikarenakan hasil t-hitung negative terhadap Keputusan Pembelian Ulang, Dari analisa diatas dapat disimpulkan bahwa terdapat pengaruh yang tidak signifikan antara layanan-layanan yang disediakan ketika memakai kartu perdana Telkomsel terhadap Keputusan Pembelian Ulang konsumen yang menjadi sample penelitian ini, maka Hipotesis dinyatakan tidak terbukti.

\section{Pengaruh Perceived Value Terhadap Keputusan Pembelian Ulang}

Berdasarkan hasil analisis data yang dilakukan dengan yang pertama dengan analisis korelasi didapatkan hasil $\mathrm{X} 2$ dan $\mathrm{Y}$ sebesar 0,489 dengan signifikan 0,000 sehingga dapat dikatakan Perceived Value memiliki korelasi yang cukup kuat terhadap Keputusan Pembelian Ulang, kedua dari perhitungan uji t Nilai t-hitung X1 6,860 lebih besar dari t-tabel $(1,661)$, maka Ho diterima dikarenakan hasil t-hitung positif maka berarti Perceived Value 
memiliki pengaruh positif terhadap Keputusan Pembelian Ulang.

Dari analisa diatas dapat disimpulkan bahwa terdapat pengaruh yang signifikan antara nilai keuntungan (perceived value) terhadap Keputusan Pembelian Ulang yang menjadi sample penelitian ini, maka Hipotesis dinyatakan terbukti.

\section{Hubungan Antara Perceived Value dengan Kualitas Pelayanan Yang Berdampak Terhadap Keputusan Pembelian Ulang.}

Dari hasil Kuesioner dengan pertanyaan "Saya berniat untuk membeli kembali setelah mengetahui kartu perdana Telkomsel memiliki nilai keuntungan (perceived value) pada beberapa layanannya." Di dapatkan hasil 18\% responden menjawab Tidak Setuju, 6\% responden menjawab Ragu, dan $76 \%$ responden menjawab Setuju dan Sangat Setuju. Maka dapat disimpulkan bahwa terdapat hubungan antara Perceived Value dengan Kualitas Pelayanan terhadap keinginan konsumen untuk Keputusan Pembelian Ulang, maka Hipotesis dinyatakan terbukti.

\section{PENUTUP}

Hasil analisis korelasi diperoleh nilai sebesar 0,654 dengan signifikan 0,000 dapat dikatakan Kualitas Pelayanan dan Perceived Value memiliki korelasi yang kuat. Kemudian Variabel X1 dan Y memiliki korelasi sebesar 0,089 dengan signifikan 0,379 sehingga dapat dikatakan Kualitas Pelayanan memiliki korelasi yang sangat rendah dengan Keputusan Pembelian Ulang. Untuk Variabel $\mathrm{X} 2$ dan $\mathrm{Y}$ memiliki korelasi sebesar 0,489 dengan signifikan 0,000 sehingga dapat dikatakan Perceived Value memiliki korelasi yang cukup kuat terhadap Keputusan Pembelian Ulang. Hal ini berarti Keputusan Pembelian Ulang dari seorang konsumen berpengaruh terhadap nilai keuntungan (perceived value) dari suatu layanan yang disediakan ketika memakai kartu perdana Telkomsel.

Dari hasil uji hipotesis terhadap hasil dari Analisis regresi linier berganda dan Uji t, diperoleh hasil. Hipotesis pertama yaitu "Pengaruh Kualitas Pelayanan (X1) Terhadap Keputusan Pembelian Ulang (Y)". Tidak terbukti dikarenakan perhitungan uji t Nilai t-hitung X1 -3,679 lebih kecil dari t-tabel $(1,661)$, maka Ho ditolak dikarenakan hasil t-hitung negative terhadap Keputusan Pembelian Ulang, hal ini didukung oleh hasil uji chi square dimana nilai Asymp. Sig dari Kualitas Pelayanan sebesar 0,412, lebih besar dari batas kritis yakni 0,05. Dengan ini dapat disimpulkan bahwa terdapat pengaruh yang tidak signifikan antara layanan-layanan yang disediakan ketika memakai kartu perdana Telkomsel terhadap Keputusan

Pembelian Ulang konsumen yang menjadi sample penelitian ini.

Hipotesis Kedua yaitu "Pengaruh Perceived Value (X2) Terhadap Keputusan Pembelian Ulang (Y)". Terbukti dikarenakan perhitungan uji $\mathrm{t}$ Nilai t-hitung X1 6,860 lebih besar dari ttabel (1,661), maka Ho diterima, dikarenakan hasil t-hitung positif, maka akan berakibat positif juga terhadap Keputusan Pembelian Ulang. Dengan ini dapat disimpulkan bahwa terdapat pengaruh yang signifikan antara nilai 
keuntungan (perceived value) terhadap Keputusan Pembelian Ulang yang menjadi sampel penelitian ini.

Dari hasil Uji Hipotesis Ketiga di dapatkan hasil $18 \%$ responden menjawab Tidak Setuju, 6\% responden menjawab Ragu, dan $76 \%$ responden menjawab Setuju dan Sangat Setuju, terhadap niat untuk membeli kembali kartu perdana Telkomsel. Maka dapat disimpulkan bahwa terdapat hubungan antara nilai keuntungan (perceived value) dengan kualitas pelayanan yang berdampak pada keputusan pembelian ulang hal ini ditimbulkan dari keinginan seorang konsumen terhadap nilai keuntungan setelah mempelajari dan mengetahui layanan-layanan yang disediakan ketika memakai kartu perdana Telkomsel.

\section{DAFTAR PUSTAKA}

Ackaradejruangsrii, $\quad$ P.. 2013.. Thee"Effect of Product "Quality Attributes Consumers Buying Decision. Journal of Asia Pasific Studies, 33: 12-24."

Adhi, Laksista \& Winda, Pradini. 2007. Analisis Pengaruh Kualitas Pelayanan dan Brand Image Terhadap Minat Beli Ulang Pada Restoran Kentucky Fried Chiken (KFC). Jurnal Fakultas

Ekonomika dan Bisnis Universitas Kristen Satya Wacana.

Chang Hsin Hsin, Wang HsinWei.2011.The Moderating Effect Of Customer Perceived Value on Online Shopping Behavior. Online Information Review.35(3).333-359
Cobb-Walgren, Cathy, Chyntia A.Ruble, dan Naveen Donthu. 1995. "Brand Equity, Brand Preference and Purchase Intent". Journal of Advertising, 24 (3), pp.25-40.

Cooper, D.R., \& Emory, C.W. 1998. Metode Penelitian Bisnis, Jilid I. Jakarta: Erlangga.

Cronin, J.J. and S.A. Taylor. 1992. "Measuring Service Quality: A Reexamination and Extention", Journal of Marketing, Vol. 56 (July), pp. 55-68.

Culiberg, B. Rojsek, I. 2010. Identifying Service Quality Dimensions As Antecedents To Customer Satisfaction in Retail Banking. Economic and Business Review. 12(3). 151-166.

Dessy, 2012. pengaruh perceived value terhadap repurchase intention. fisip UI 2012

Firend A. Rasheed, Masoumeh F. Abadi. 2014. Impact of service quality, trust and perceived value on customer loyalty in Malaysia services industries. Universiti Teknologi Malaysia. International Conference on Accounting Studies 2014, ICAS 2014, 18-19 August 2014, Kuala Lumpur, Malaysia

Lurensia. 2017. Analisis pengaruh kualitas pelayanan dan kualitas produk terhadap minat beli ulang (Studi pada Starbucks Semarang).

Marieta. 2017. Pengaruh kualitas pelayanan terhadap niat beli ulang (Studi Kasus pada Coffee Legend Yogyakarta).

Melysa, 2013. Kualitas pelayanan, kualitas produk dan harga 
pengaruhnya terhadap loyalitas pelanggan kartu as telkomsel di kota manado. Jurnal EMBA. Vol.1 No.4 Desember 2013, Hal. 86-94

Nadya, 2015. Pengaruh kualitas pelayanan terhadap minat pembelian ulang. E-Proceeding of Management : Vol.2, No.3 Desember 2015: 2419

Oliver Richard, L. 1997. Satisfaction: A behavioral perspective on the consumer. New York NY: Irwinmcgraw-Hill.

Parasuraman, Zeithaml, V. A., \& Berry, L. L. 1985. A conceptual model of service quality and its implications for future research. The journal of marketing, 41-50. Parasuraman, Zeithaml, V. A., \& Berry, L. L. 1988. Servqual. Journal of retailing, 64(1), 12-40.

Reichheld, F. F., \& Sasser, W. E. (1990). Zero defections: quality comes to services. Harvard business review, 68(5), 105-111.

Reichheld, F. F., \& Teal, T. 1996. The loyalty effect: The hidden force behind growth, profits and lasting value (Boston, MA, Harvard Business School Press).

Rust, R. T., Zeithaml, V. A., \& Lemon, K. N. 2001. Driving customer equity: How customer lifetime value is reshaping corporate strategy: simonandschuster.

Yap, B. W., Ramayah, T., \& Shahidan, W. N. W. 2012. Satisfaction and trust on customer loyalty: a PLS approach. Business Strategy Series, 13(4), 154-167.

Zeithaml, V. A. 1988. Consumer perceptions of price, quality, and value: a means-end model and synthesis of evidence. The journal of marketing, 22.

Zeithaml, V. A., Berry, L. L., \& Parasuraman, A. 1996. The behavioral consequences of service quality. The journal of marketing, 31-46.

Anonymous. Tentang Data Jumlah Kartu Perdana

(www.katadatanewsandresearch.co $\underline{m})$. Diunduh Tanggal 18 Maret 2018 Anonymous. Tentang Sejarah Singkat Telkomsel (www.telkomsel.com/aboutus) . Diunduh Tanggal 8 April 2018. 